\title{
A Postcode Lottery? Regional Variations in Electricity Prices for Inactive Consumers
}

\author{
David Deller \\ Centre for Competition Policy \\ University of East Anglia \\ Glen Turner \\ Centre for Competition Policy \\ University of East Anglia \\ Catherine Waddams Price \\ Centre for Competition Policy \\ Norwich Business School \\ University of East Anglia \\ CCP Working Paper 18-10
}

\begin{abstract}
The introduction of a price cap for consumers who have not switched to cheaper deals in the British energy market reflects increasing political concern about the higher prices paid by these consumers compared with their more active counterparts. In this paper, we demonstrate the variations in prices paid by inactive consumers for electricity in different parts of Britain over the last 45 years. The regions identified as the cheapest and most expensive vary noticeably over the period, while the magnitude of the regional differences are, if anything, lower since the introduction of competition than they were before privatisation. We explore the characteristics of consumers who stated that they had never switched supplier, and who were therefore subject to these regional price differences, using unique data from a consumer survey in 2011. Responses to the question 'have you ever switched supplier' identified several characteristics of inactive consumers which were consistent with the findings of previous studies: not being retired, having lower electricity expenditure, not having a gas supply and using certain payment methods are associated with a consumer reporting never having switched. However applying a consistency test (namely observing whether consumers reported being with their region's incumbent supplier) highlighted a number of issues with relying solely on survey data to identify long-term inactivity.
\end{abstract}

Contact Details:

David Deller

David.Deller@uea.ac.uk 


\title{
A Postcode Lottery? Regional Variations in Electricity Prices for Inactive Consumers
}

\author{
David Deller ${ }^{1}$, Glen Turner and Catherine Waddams Price ${ }^{2}$ \\ Centre for Competition Policy, University of East Anglia ${ }^{3}$
}

This version: January 2019

\begin{abstract}
The introduction of a price cap for consumers who have not switched to cheaper deals in the British energy market reflects increasing political concern about the higher prices paid by these consumers compared with their more active counterparts. In this paper, we demonstrate the variations in prices paid by inactive consumers for electricity in different parts of Britain over the last 45 years. The regions identified as the cheapest and most expensive vary noticeably over the period, while the magnitude of the regional differences are, if anything, lower since the introduction of competition than they were before privatisation. We explore the characteristics of consumers who stated that they had never switched supplier, and who were therefore subject to these regional price differences, using unique data from a consumer survey in 2011. Responses to the question 'have you ever switched supplier' identified several characteristics of inactive consumers which were consistent with the findings of previous studies: not being retired, having lower electricity expenditure, not having a gas supply and using certain payment methods are associated with a consumer reporting never having switched. However applying a consistency test (namely observing whether consumers reported being with their region's incumbent supplier) highlighted a number of issues with relying solely on survey data to identify long-term inactivity.
\end{abstract}

\footnotetext{
${ }^{1}$ Corresponding author: Dr David Deller, Centre for Competition Policy (CCP), University of East Anglia, Norwich Research Park, Norwich, Norfolk, NR4 7TJ, email: david.deller@uea.ac.uk.

${ }^{2}$ Also of Norwich Business School, University of East Anglia

${ }^{3}$ This research was undertaken as part of the UK Energy Research Centre's research programme. The authors are grateful to Monica Giulietti and several research associates for help in collating the data and to Cornwall Insight for providing access to recent price data.
} 


\section{Introduction}

The wide variation in the prices which households pay for energy because of their different engagement levels has generated considerable concern and debate about residential energy markets in Britain. ${ }^{4}$ Feelings of the need for fair outcomes in the sector contribute to its high political salience and, in turn, this political salience has resulted in legislation to cap the prices charged to those who are on more expensive default tariffs from the beginning of $2019^{5}$. Because low-income households devote a higher proportion of their expenditure to energy than their richer counterparts (Deller and Waddams Price, 2018), these price variations have sharper implications for these households. However, regional variations in the prices ${ }^{6}$ paid by consumers who have never switched supplier have received less attention. We take a long-term perspective to explore how the prices paid by electricity consumers supplied by the incumbent supplier in different regions of Great Britain have varied over the 46 years from 1970 to 2016, and identify the most expensive and cheapest areas. We use a unique survey from 2011 to characterise those who say they have never switched, and so are likely to be paying these prices; although, a consistency check reveals some challenges in identifying this group without access to supplier data. Our analysis covers the evolution of the sector from nationalised regional companies to privatised retailers and, thus, provides historical context for these changes and current policy concerns.

We find persistent and significant regional differences in the charges faced by consumers who have been served by incumbents. In 1970 the annual difference between the most expensive and cheapest region was $£ 143$ (in 2016 prices), representing 33\% of the national average bill. The highest differences between regions were in the early 1970s, and again a decade later; more recently (between 2009 and 2016) the variation for Standard Credit Tariffs (SCTs) has been between $8 \%$ and $18 \%$ of the national average bill. While these differences are smaller than some available from switching supplier/tariff in recent years (the latter motivating the government imposition of price caps), they nevertheless constitute a non-trivial part of consumers' energy bills.

However these regional differences are unstable, in the sense that different regions have been the cheapest/most expensive at different times. The north of Scotland has changed from being one of the cheapest regions, until the early 1980s, to one of the most expensive regions from the late 2000s, while London, which was the most expensive region in the early 1980s, has become one of the cheapest regions in recent years.

To explore the characteristics of consumers who stayed with their regional incumbent, we use a consumer survey from 2011 to identify those who reported that they had never switched electricity supplier. The consumers who report never switching, and who therefore likely pay the price charged by their regional incumbent, possess similar characteristics to those revealed in other surveys. Not being retired, renting from a private landlord, reporting lower electricity expenditure and paying other than by direct debit or standing order are positively associated with reporting they have never switched. However a consistency check (identifying those respondents reporting the incumbent as

\footnotetext{
${ }^{4}$ For example, see pg417-pg425 and pg524-538, CMA (2016a)

${ }^{5}$ See Domestic Gas and Electricity (Tariff Cap) Act 2018, available at:

http://www.legislation.gov.uk/ukpga/2018/21/contents/enacted/data.htm . These government imposed price caps are in addition to those introduced by the regulator on prepayment tariffs in 2017 and for some vulnerable consumers in 2018.

${ }^{6}$ Our analysis is based on the bill for a set quantity of annual electricity consumption. By fixing the quantity consumed we are effectively comparing the average price of electricity between regions and time periods.
} 
their current supplier) raises some questions about identifying persistent non-switchers, and the reliability of similar findings from other surveys, unless they can be confirmed by data from supplier databases.

In the next section we describe the development of British energy retailing over the period studied, and in Section 3 we explain our data and methodology. Section 4 presents the results on the price differences between regions and identifies the characteristics of those who report never switching, as well as exploring some challenges of using this declaration to identify persistent non-switchers. Section 5 concludes and discusses the policy implications of our findings.

\section{British energy retailing and relevant literature}

To explain how inactive consumers retain supply by their incumbent on an SCT, here we outline the background of the British retail energy sector, its opening to competition and traditional payment methods. We then review more recent regulatory developments and literature relevant to the current study.

\subsection{A history of British energy retailing}

The current incumbent companies are the successors to the Area Electricity Boards in each of the fourteen electricity regions in Great Britain. These Area Boards were nationalised in 1948, and continued as publicly owned and operated companies until their privatisation as Regional Electricity Companies (RECs) in 1990. Until the markets opened, each REC was responsible for arranging the supply and distribution of electricity within its own geographic region (see Figure 1), and was individually managed under government ownership. As part of the privatisation programme, markets were opened in stages, first for industrial and commercial consumers in 1990 and 1994 respectively, while all residential consumers were given a choice of suppliers by 1999. Our data, from 1970 to 2016, cover the nationalised, privatised monopoly and post market opening periods.



Figure 1: The 14 Regional Distribution Areas in Great Britain ${ }^{7}$

The traditional method of paying for electricity (which we refer to as the Standard Credit Tariff, SCT) was to pay a bill issued quarterly and based on the previous quarter's metered consumption. We

\footnotetext{
${ }^{7}$ Source: http://www.energybrokers.co.uk/electricity/PES-Distributor-areas.htm (accessed 19 January 2019)
} 
concentrate on SCTs, both because it was the most common payment method over the period as a whole, and because it is the default payment method for consumers who take no action, i.e. the inactive customers who are the focus of our study. ${ }^{8}$ SCTs have traditionally been variable, in the sense that the supplier can adjust the price periodically, after giving the consumer notice. Since market opening, both entrant and incumbent companies have offered a variety of discounts for payment by direct debit and online account management for both 'indefinite ${ }^{9}$ and fixed term tariffs.

When energy markets were first opened, each of the former electricity monopolies inherited its own consumer base and (together with the gas incumbent, British (Scottish) Gas, and entrants from outside the sector) entered other electricity regions (and the national gas market) to attract consumers from the local incumbent. There were a number of mergers in the years following market opening, both between the incumbent companies themselves and between incumbents and entrants who were new to British energy supply. There were also many exits, so that by 2002 the five consolidated descendants of the RECs each served two or three regions as incumbent supplier and, together with the gas incumbent, accounted for almost all residential supply. In the same year, the British energy regulator, Ofgem, judged that competition had developed sufficiently to remove the remaining caps on the retail prices of both electricity and gas (though price control continues for network operations). The 'Big Six' descendants of the electricity and gas incumbents continue to dominate residential energy supply, albeit with increasing entry from smaller companies after 2012. By June 2018 these 'new' entrants supplied almost a quarter of the market (Ofgem, 2018). However, our focus is specifically consumers who stayed with their electricity incumbent, and the prices these consumers paid, rather than the alternative prices offered by entrants. As of September 2018, 27\% of British customers were supplied by their regional incumbent ${ }^{10}$, though not all were on an SCT.

Since most domestic consumers purchase gas as well as electricity, it is worth noting that the regional story is rather different for gas. After its formation from 12 regional gas boards in 1972, British Gas harmonised the different tariffs which it inherited, so that by 1989 it charged a geographically uniform tariff (Monopolies and Mergers Commission, 1993). British Gas maintained a uniform gas price for its SCT until July 2008, when some regional differences were introduced.

\subsection{Increasing regulatory intervention}

Initial optimism about the market, following the removal of retail price caps, turned to concern, particularly for consumers who were inactive in the market. In 2008 Ofgem started a series of investigations into how well the residential market was performing, and introduced a variety of policies to protect consumers, including geographic non-discrimination clauses (see Ofgem, 2008, and Hviid and Waddams Price, 2012) and, later, limits on the number of tariffs which suppliers could charge ${ }^{11}$. Discussion has focused on the implicit harm experienced by customers who do not switch,

\footnotetext{
${ }^{8}$ Some consumers in debt to their supply company, or who have no credit rating, may be put on a prepayment meter, but these account for less than a fifth of consumers throughout the period studied. There were also a number of time-of-use tariffs, many introduced in the 1970s, however, the extent of their use varied by region. ${ }^{9}$ Generally called variable, or sometimes 'evergreen' tariffs.

${ }^{10}$ See Table 2.4.1 Percentage of domestic electricity customers by region by supplier type (QEP 2.4.1), Statistical data set - Quarterly domestic energy customer numbers, Department for Business, Energy and Industrial Strategy, available at: https://www.gov.uk/government/statistical-data-sets/quarterly-domesticenergy-price-stastics (accessed 16 January 2019)

${ }^{11}$ See pg569-577, CMA (2016a).
} 
in terms of the higher prices they pay, with the additional concern that these non-switchers include a larger proportion of low income and vulnerable customers.

The Competition and Markets Authority (CMA) criticised both the non-discrimination clauses and the limits on tariff numbers in their 2016 report $^{12}$, which found an Adverse Effect on Competition from weak consumer response. Due to particular barriers to switching in the prepayment market, the CMA recommended a cap on prepayment prices, but the majority of the panel rejected a more general cap on prices for consumers not active in the market. However, the (Conservative) government promised a price cap on 'default' tariffs (the tariffs paid by inactive consumers) in its 2017 election manifesto, and in 2018 introduced legislation requiring the regulator to impose such constraints. Given the concerns about the higher prices paid by inactive consumers compared to active consumers, it seems important to investigate and explore the regional differences in charges between inactive consumers. However, we do not take a view as to whether the differences we observe are a 'problem' or not.

\subsection{Relevant literature}

Official statistics have been published providing information on average prices, bills and market shares by UK region for recent years (for example, see Department for Business, Energy and Industrial Strategy, 2017); these statistics provide the main source of information on British residential energy price levels. Some academic papers have analysed the costs of constituent parts of the energy bills, including wholesale prices and long term residential costs (for example, Fouquet, 2011). Also, using self-reported expenditures from national surveys, Deller and Waddams Price (2018) show that since market opening in 1997 median energy expenditure, in real terms, stayed fairly stable up to 2003, before rising to be $26 \%$ above its 1997 level by 2013 . We believe the present paper is the first description of regional residential electricity prices over the extended period from 1970 to 2016. As such, the current paper provides important historical context for the current debate on price differentials, which is becoming an increasing policy issue both in energy and other sectors.

Additionally, several papers have analysed consumer switching in residential energy markets, often exploring why low switching rates are observed despite apparently sizeable monetary savings being available. Survey data have been used to identify the factors associated with changing supplier, both in the UK and the US (see Deller et al., 2017 for a review). Compared to this earlier work, the second half of the present paper does not focus on the factors associated with switching over a limited period of time, but rather on those who have never switched, thereby identifying the factors associated with the long-run behaviour of persistent non-switching. We make a methodological comment that a surprisingly high proportion of respondents give apparently inconsistent answers regarding their nonengagement with the market, suggesting potential limits to the ability of survey data alone to investigate this topic.

\footnotetext{
${ }^{12}$ CMA (2016a).
} 


\section{Data and methodology}

\subsection{The Incumbent electricity bill time series}

We have collated data from several sources ${ }^{13}$ to calculate the annual bill for electricity consumption of $3300 \mathrm{kWh}^{14}$ charged by each incumbent electricity supplier in its region each year from 1970 to $2016^{15}$. As discussed previously, our main analysis is based on the default payment method, the SCT. SCTs differ from the Standard Variable Tariffs (SVTs) often referred to in recent discussions of the market, as the latter includes (and is probably dominated by) consumers paying by direct debit. While direct debit is the most common payment method for those who have switched supplier, we do not focus on it in the main analysis as: (a) direct debit was not available to consumers in the earlier part of the time period studied, and (b) paying by direct debit requires a positive action by consumers. Figure A1 reports a time series of regional electricity bills for the direct debit payment method between 1991 and 2016.

For simplicity, we do consider the minority of customers using the other traditional payment method, prepayment (pay as you go), or traditional time of use tariffs, such as Economy $7^{16}$. The regulator found that regional variations were similar across the different tariff types (Ofgem, 2015).

The prices used to generate bills are inclusive of $\mathrm{VAT}^{17}$ and have been adjusted to 2016 values using the Retail Price Index (RPI). RPI rather than the Consumer Price Index (CPI) has been used because CPI is unavailable before 1988 and because RPI has been the traditional inflation measure used by regulators in their price caps (including for retail electricity prices between 1990 and 2002). Adjusting prices using the CPI reduces the incumbent bill size in 1988 (averaged across regions) to around $£ 460$ (in 2016 prices), around $£ 100$ less than if adjusted using the RPI. Figure A2 provides a time series of regional electricity bills between 1988 and 2016, converted to 2016 prices using the CPI. As Figure A2 shows, the main impact of using CPI is that electricity prices after 2009 are noticeably higher than those in the late 1980s/early 1990s.

\subsection{Analysis of persistent non-switchers}

To explore the characteristics of persistent non-switchers, we used unique data from a survey of consumers undertaken by the Centre for Competition Policy in 2011, twelve years after market opening (see Flores and Waddams Price, 2018 for details of the survey). The survey was designed to be representative of households in England, Scotland and Wales. The main analysis was based on responses to the question "Have you ever had your electricity supplied by a different company?", and we refer to this as the 'Never Switched' variable. Analysis in the present study was restricted to the

\footnotetext{
${ }^{13}$ The sources include data gathered in previous projects at the University of Warwick; data collected by the Centre for Competition Policy from price factsheets published by Which?, energywatch and Consumer Focus; and more recent data from Cornwall Insight.

${ }^{14}$ The regulator used 3300kWh per year as a typical 'medium' consumption level for residential consumers between 1998 and 2013. Average consumption levels vary between regions, partly because of availability of piped natural gas, and Ofgem's view of 'medium' consumption had fallen to $3100 \mathrm{kWh}$ per year by 2018. Using $3300 \mathrm{kWh}$ per year throughout the time period enables us to focus on price differences.

15 Unfortunately, in more recent years there are some gaps in the data. In particular, no data was available for 2014; in the Figures straight lines connect the 2013 and 2015 data points. Prices are charged in April each year. ${ }^{16}$ Economy 7 gives cheaper electricity at night and was widely promoted in the $1970 \mathrm{~s}$.

17 Prior to 1994 no VAT was charged on domestic fuels. In 1994 a VAT rate of $8 \%$ was applied and this was reduced to $5 \%$ in 1997.
} 
sub-sample of respondents aged 30 or over, so as to rule out respondents who had not been an adult (i.e. were too young to be responsible for an electricity bill) at the time of market opening.

To analyse factors associated with respondents who had never switched prior to the 2011 survey a logit model is used. This allows the household characteristics with the strongest association to reporting never switching to be identified after controlling for a comprehensive range of other factors. The dependent variable, $z_{i}$, takes a value of 1 when a respondent has never switched electricity supplier and a value of 0 when a respondent has switched at least once. For each respondent the probability, $p_{i}$, of never switching is:

$$
z_{i}=\left\{\begin{array}{rrr}
1 & \text { with probability } & p_{i} \\
0 & \text { with probability } & 1-p_{i}
\end{array}\right\}
$$

where the probability of never switching, $p_{i}$, is modelled as:

$$
p_{i}=\operatorname{Prob}\left(z_{i}=1 \mid \boldsymbol{x}_{\boldsymbol{i}}\right)=F\left(\boldsymbol{x}_{\boldsymbol{i}}{ }^{\prime} \boldsymbol{\gamma}\right)
$$

Here $p_{i}$ is the probability a respondent has never switched given the vector of explanatory values for respondent $i, \boldsymbol{x}_{\boldsymbol{i}}$. This probability can be expressed as a function of $\boldsymbol{x}_{\boldsymbol{i}}$ multiplied by the coefficients for each variable found through the regression process, $\gamma$. Using the logit model assumes the error process for the latent variable behind the model is logistically distributed and $F($.$) is the logistic$ cumulative distribution function. The model is estimated using maximum likelihood estimation.

In Section 4.2.1 average marginal effects are reported indicating the average percentage point increase in the probability of never switching associated with a change in a particular explanatory variable. The full set of explanatory variables included in the regressions are: age, household income, educational qualifications, employment status, tenure, type of dwelling, whether had a broadband connection, government office region, an area's rurality, whether had a gas connection, payment method, estimated electricity ${ }^{18}$ expenditure, respondent gender and whether had children.

The survey data also allowed a potential robustness check of the Never Switched variable, as for those respondents whose location we knew in sufficient detail, we could see whether they named their regional incumbent as their supplier. As an intuitive starting assumption one might expect those households reporting Never Switched to name their regional incumbent as their supplier. However, as discussed in Section 4.2.2 the Never Switched and With Incumbent variables were often inconsistent. In Section 4.2.2 a range of potential explanations for these apparent inconsistencies are discussed.

Only for an unrepresentative sub-sample of respondents ${ }^{19}$ is their geographic location known with sufficient precision to construct the With Incumbent variable. In Appendix 5, we report separate logit regressions based on the With Incumbent subsample where the dependent variable is respectively: (i)

\footnotetext{
${ }^{18}$ For the roughly third of respondents who had a combined gas and electricity bill, this variable represents their estimated energy expenditure.

${ }^{19}$ The 'With Incumbent' variable was reliant on either a respondent providing their postcode or stating an electricity supplier that could not be the regional incumbent in their government office region (government office regions and electricity supplier regions overlap imperfectly).
} 
'Never Switched' and (ii) 'With Incumbent'. This and the discussion in section 5 highlights methodological points about attempting to identify long term inactivity from survey data alone.

\section{Regional Price Differences}

We first examine geographic variations in the electricity bills charged by incumbent companies between 1970 and 2016, which includes the period of privatisation (after 1990) and competition (after 1999). In section 4.2 we discuss the characteristics of those who said they had never switched and some challenges of identifying persistent non-switchers.

\subsection{Incumbent bills in each region}

Figures $2 \mathrm{~A}$ and $2 \mathrm{~B}$ show the SCT bills (in 2016 prices), charged by the incumbent in each region for a consumer using $3300 \mathrm{kWh}$ of electricity per annum. A subset of regions in Figure 2B allows identification of particularly notable variations in time patterns across regions. Vertical bars have been added to graphs to show when the RECs were privatised, competition was introduced and the final caps on retail tariffs were removed. These lines have been added solely for reference and we do not seek to formally identify the impact of these events on the time series we report.



Figure 2A: Incumbent bill size by electricity supply region for the standard credit tariff, $3300 \mathrm{kWh}$ per year, 1970-2016 


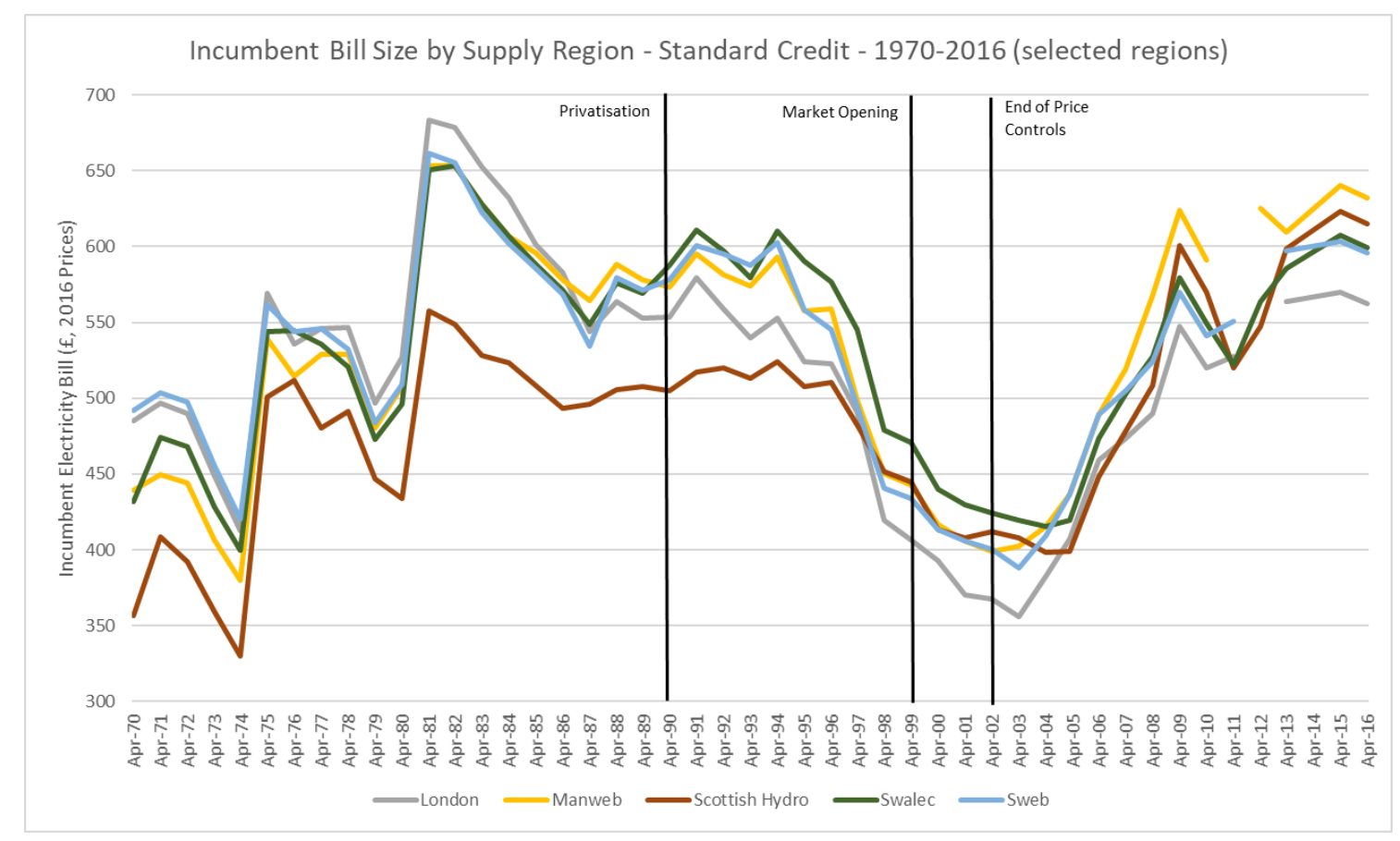

Figure 2B: Incumbent bill size by electricity supply region for the standard credit tariff, 3300kWh per year, selected regions

Figures $2 \mathrm{~A}$ and $2 \mathrm{~B}$ show a common general pattern over time, but with considerable variation between regions. In the context of the 40-year time period, real electricity prices were unusually low in the early 2000s. Incumbent prices have risen since 2003 to levels broadly similar to those in the early 1980s for most regions, though in Scotland prices have risen above their peak in the early 1980s. The two energy price shocks of the 1970s are also clearly visible. While all areas follow this general pattern, considerable variations between the electricity supply regions remain, both at any moment in time and in their relative movement over time. In particular, Figure 2B shows a substantial difference in the reductions in bills in the London and Scottish Hydro regions between 1981 and 2003: the average bill in the London region fell by almost $£ 330$ compared to only $£ 150$ in the Scottish Hydro region. 


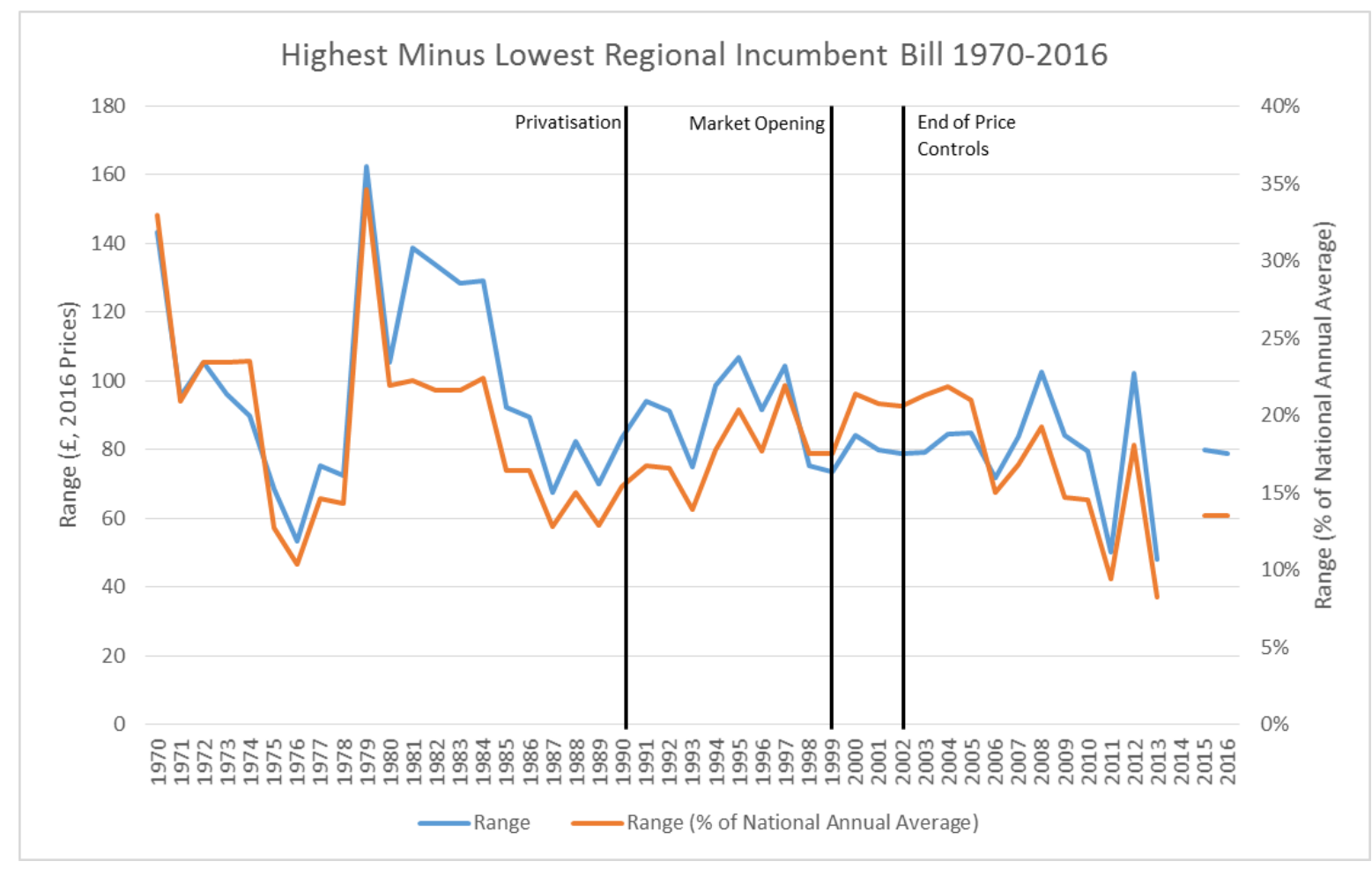

Figure 3: The range in incumbent bills across electricity supply regions (standard credit tariff, 3300kWh per annum)

Figure 3 shows that the range between the highest and the lowest incumbent electricity bills across regions also varies over the time period, with relative stability following considerable fluctuations before the mid-1980s. Prices charged by regional incumbents converged in the early 1970s, before they diverged in both (absolute and percentage terms) as prices rose at the end of that decade. Apart from the peak in 1979 (which may be due to data issues), the range is greatest in absolute terms in 1970 and 1981, and is lowest (at around f50) in 2011 and 2013. In relative terms (the right hand axis), the range is highest in 1970 at over $30 \%$ of the bill and lowest in 2013 at $8 \%$ of the bill.

Figure 4 shows the identity of the most expensive region also varies over time. Through much of the period the South West (Sweb) and Wales (Swalec and Manweb) had among the most expensive bills (probably driven by transmission charges and their distance from generating plants). Scottish Hydro bills, which were among the cheapest in the 1980s, moved to be amongst the most expensive by the late 1990s (all the movement occurred between 1994 and 1999), with their position being rather volatile during the 2000s. Bills in Scotland were particularly affected by new trading arrangements, as well as other policy changes. London, which was the most expensive region between 1980 and 1986 moved in the opposite direction being the second cheapest region in 2008. Compared to this considerable variability, between 1990 and 2003, in all but one year, South Wales (Swalec) had the most expensive electricity bill. After 2009 Merseyside and North Wales (Manweb) was the most expensive region (when data was available). 


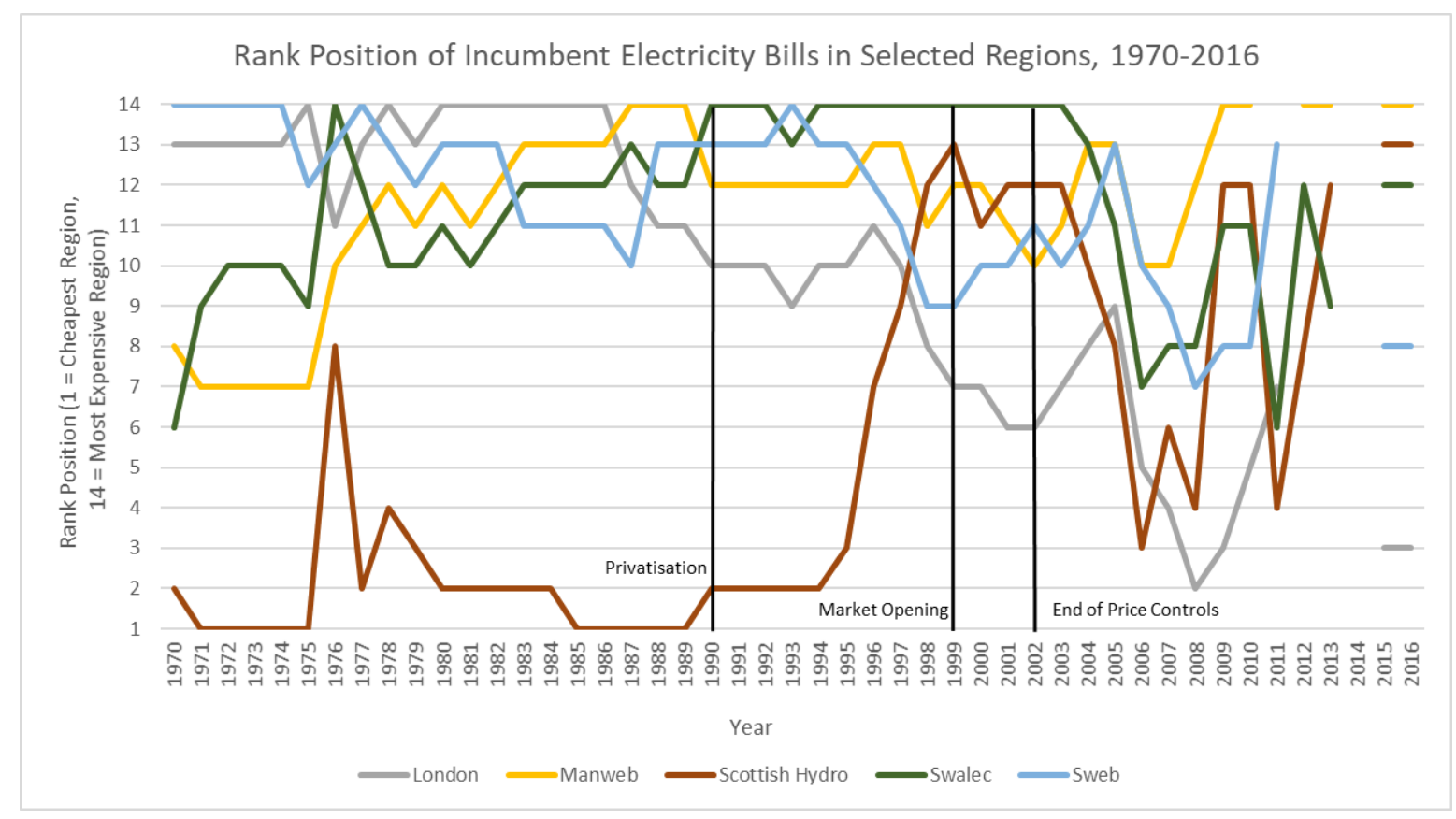

Figure 4: The rank position of incumbent electricity bills (from cheapest to most expensive) for selected regions

Figure 5 shows that over the period as a whole, a customer using 3,300 kWh per year who stayed with the incumbent in South Wales (Swalec) paid on average around $£ 49$ a year more than one who lived in the Scottish Hydro region. For the period as whole this equates to a total difference of just over $£ 2,100$. Sweb and Manweb also had bills that on average were more than $£ 45$ above those in the Scottish Hydro region. Appendix 2 provides evidence on factors that may influence the regional price differences identified in this section; rather than attributing formal causation, Appendix 2 is designed merely to contextualise the main results.

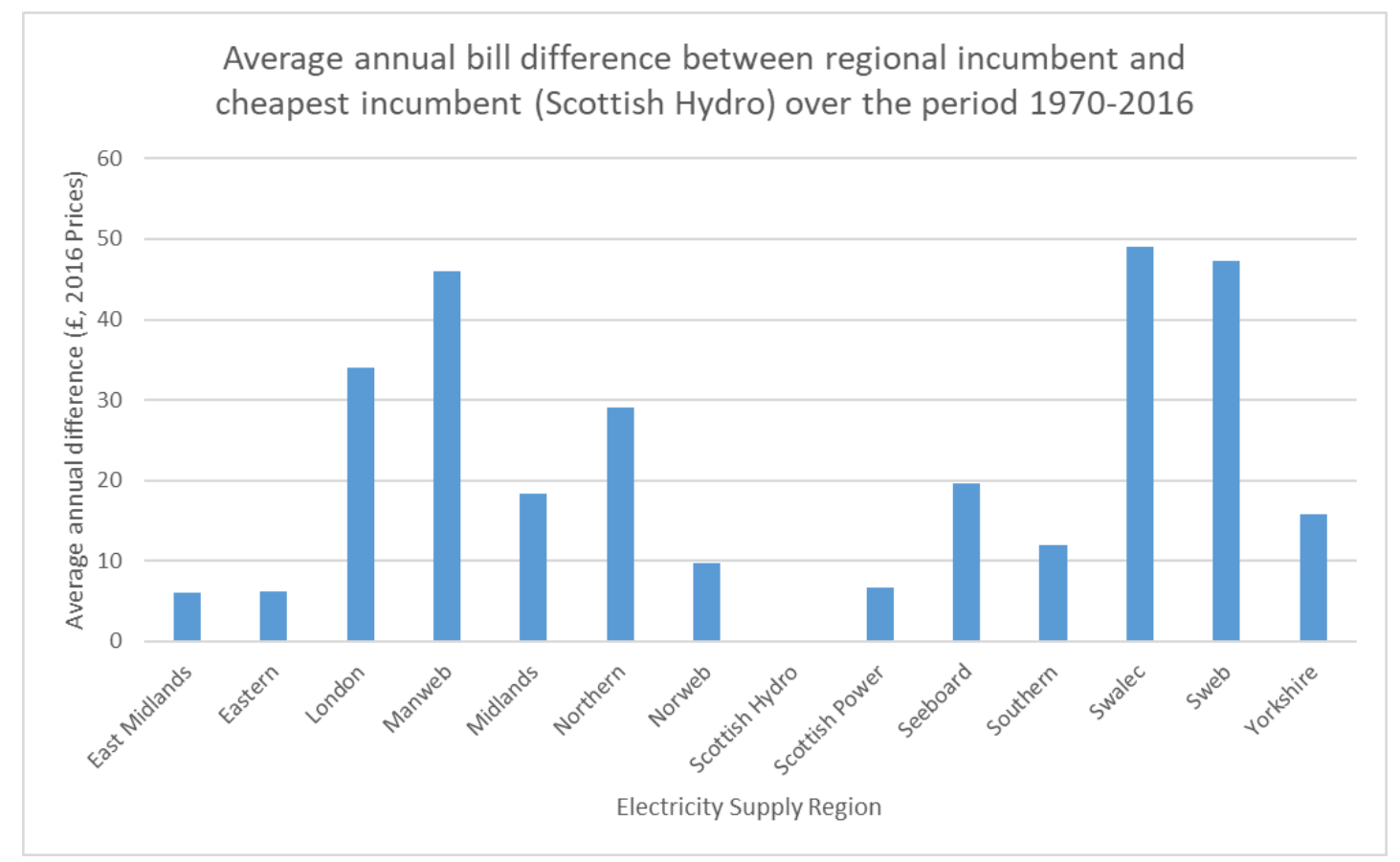

Figure 5: Annual bill difference between each regional incumbent and the overall cheapest region averaged across 1970 to 2016 


\subsection{Identifying persistent non-switchers and their characteristics}

Having described the differences in electricity bills between regions, in this section we attempt to identify the types of households that remain with their regional incumbent and, thus, are subject to the regional price differences described above. Understanding the type of households which persistently do not switch is also of per se interest given that the CMA (2016a) argued that a lack of consumer engagement had an adverse affect on competition in the energy market.

\subsubsection{Consumers who said they had never switched}

In this subsection we explore the characteristics of respondents who answered 'No' when asked whether they had ever received electricity from a supplier other than their present supplier, i.e. respondents who reported they had Never Switched. In Table 1 we report the results of multivariate logit regressions where Never Switched is the dependent variable. For brevity, In Table 1 we focus on those variables showing some statistical significance. In Appendix 3.1 univariate logit regressions are reported which show the associations between individual variables and Never Switched. ${ }^{20}$

We ran separate regressions including and excluding respondents' electricity payment method used and their estimated electricity bill, in case these variables introduced reverse causality/endogeneity issues. For example, one might be concerned that paying by direct debit is the result of having switched rather than something influencing a person's decision to switch.

\footnotetext{
${ }^{20}$ The results of these univariate regressions are comparable to the descriptive statistics presented in CMA (2016b).
} 


\begin{tabular}{|c|c|c|c|}
\hline & (1) & (2) & (3) \\
\hline Age linear & $-0.010^{*}$ & $-0.015^{* *}$ & -0.009 \\
\hline Age squared & $0.000 * *$ & $0.000 * * *$ & $0.000 * *$ \\
\hline Income: $£ 35,000-49,999$ & - & - & - \\
\hline Income: Refused & $0.148^{* * *}$ & $0.137^{* * *}$ & $0.119 * * *$ \\
\hline No Qualifications & - & - & - \\
\hline $\begin{array}{l}\text { O-Level, A-Level, HNC, GNVQ, } \\
\text { NVQ/SVQ Level 1-3, GCSE, CSE, } \\
\text { City \& Guilds }\end{array}$ & $-0.062 * *$ & 0.005 & -0.043 \\
\hline $\begin{array}{l}\text { Degree, Postgraduate, NVQ/SVQ } \\
\text { Level 4, HND, HNVQ }\end{array}$ & $-0.090 * *$ & -0.029 & $-0.065^{*}$ \\
\hline Employed full-time & - & - & - \\
\hline Self-employed & $-0.100 * *$ & -0.072 & $-0.102 * *$ \\
\hline Retired & $-0.187^{* * *}$ & $-0.205^{* * *}$ & $-0.184 * * *$ \\
\hline Owned Outright & - & - & - \\
\hline Rented from Private Landlord & $0.165^{* * *}$ & $0.108^{* *}$ & $0.131^{* * *}$ \\
\hline Detached & - & - & - \\
\hline Terraced & -0.057 & -0.046 & $-0.072 * *$ \\
\hline Other & $-0.164 *$ & $-0.218^{* * *}$ & $-0.188 * *$ \\
\hline Broadband: Yes & - & - & - \\
\hline Broadband: No & $0.078^{* *}$ & 0.052 & 0.038 \\
\hline London & - & - & - \\
\hline Scotland & -0.003 & 0.063 & 0.012 \\
\hline Wales & 0.117 & $0.142^{*}$ & $0.117^{*}$ \\
\hline West Midlands & $-0.178^{* * *}$ & $-0.164 * * *$ & $-0.165 * * *$ \\
\hline Yorkshire and the Humber & $-0.100 *$ & $-0.111^{* *}$ & $-0.095^{*}$ \\
\hline Metropolitan & - & - & - \\
\hline Other $100 \%$ Urban & $-0.102 * *$ & $-0.093 * *$ & $-0.106^{* *}$ \\
\hline Mixed Urban/Rural & $-0.134^{* * *}$ & $-0.143 * * *$ & $-0.143^{* * *}$ \\
\hline Rural & -0.025 & -0.040 & -0.035 \\
\hline Gas Connection: No & $0.211^{* * *}$ & $0.223^{* * *}$ & $0.219 * * *$ \\
\hline Gas Connection: Yes & - & - & - \\
\hline Direct Debit /Standing Order & & - & - \\
\hline $\begin{array}{l}\text { In person at post office } \\
\text { /bank/building society }\end{array}$ & & $0.195^{* * *}$ & $0.184^{* * *}$ \\
\hline $\begin{array}{l}\text { Over the internet with } \\
\text { credit/debit card }\end{array}$ & & $0.157^{* *}$ & $0.154^{* *}$ \\
\hline By post & & $0.203^{* *}$ & $0.194 * * *$ \\
\hline Pre-payment & & $0.135 * * *$ & $0.147^{* * *}$ \\
\hline
\end{tabular}

(Continued on next page) 
(Continued from previous page)

\begin{tabular}{|c|c|c|c|}
\hline & (1) & (2) & (3) \\
\hline $\begin{array}{l}\text { Estimated electricity expenditure } \\
\text { (continuous, quadratic, } £ 100 \\
\text { units) }\end{array}$ & \multicolumn{3}{|c|}{$-0.016 * * *$} \\
\hline Est. Bill: Don't Know & & & 0.041 \\
\hline Up to $f 200$ & & & 0.129 \\
\hline f199 to $£ 300$ & & & 0.052 \\
\hline$£ 299$ to $£ 400$ & & & -0.014 \\
\hline$£ 399$ to $£ 500$ & & & 0.003 \\
\hline$£ 499$ to $£ 600$ & & & -0.022 \\
\hline$£ 599$ to $£ 700$ & & & - \\
\hline$£ 699$ to $£ 800$ & & & $-0.112^{* *}$ \\
\hline$f 799$ to $£ 900$ & & & -0.075 \\
\hline f899 to $£ 1000$ & & & -0.095 \\
\hline$£ 999$ to $£ 1200$ & & & $-0.118^{* *}$ \\
\hline f1199 to $f 1400$ & & & $-0.116^{* *}$ \\
\hline f1399 to $f 2400$ & & & $-0.150 * * *$ \\
\hline$£ 2400$ and over & & & 0.017 \\
\hline $\mathrm{N}$ & 1766 & 1434 & 1766 \\
\hline Log likelihood & -1082.374 & -831.981 & -1044.911 \\
\hline P-value, LR test joint significance & 0.000 & 0.000 & 0.000 \\
\hline
\end{tabular}

Notes: * indicates statistical significance at the $10 \%$ level, ${ }^{* *}$ indicates significance at the $5 \%$ level, and ${ }^{* * *}$ indicates signifcance at the $1 \%$ level. Bold indicates the base category for categorical variables. The reported figures are the average marginal effects associated with the probability of reporting having never switched electricity supplier. We focus on reporting the categories of variables that showed significance at the $5 \%$ level in at least some of the multivariate regressions. Where the table includes a blank space the specified variable was not included in the specified regression. Additional variables included in the regressions, but where none of the categories were significant at the $5 \%$ level are: respondent gender and whether has children. The number of observations drops in column 3 because using the continuous electricity expenditure variable involves dropping responses of 'don't know' regarding el ectricity expenditure.

Table 1: Average marginal effects of household characteristics on the probability of a household reporting Never Switched (base categories in bold)

Many characteristics of those who say they have never switched are consistent with findings from the literature, although, the literature is more usually framed in terms of who has changed supplier in the immediate past ${ }^{21}$.

However the results appear to differ from past findings regarding age. Table 1 indicates a U-shaped relationship, implying the middle aged are less likely to report never switching (i.e. more likely to have switched at some point) than either their older or younger counterparts, with those in their midforties least likely to report that they have never switched. In contrast, most other studies (Giulietti et al., 2005, Waddams Price and Zhu, 2016,) find the middle aged are least likely to switch, so we might

\footnotetext{
${ }^{21}$ In particular, Flores and Waddams Price, 2018, use data from the same survey to identify the role of attitudes in switching behaviour.
} 
expect them to be more, rather than less, likely to report that they have never done so. Part of the explanation may be the difference between stock and flow: older age groups are more likely to report never switching, because as middle aged consumers at market opening they were less likely to be active. Also, the reported relationship between age and never switching is after controlling for retirement status. Tables 1 shows retirement (i.e. being retired versus being employed full-time) is associated with a lower probability of reporting 'never switched'. Separating the effect of retirement from age is likely to be part of the reason for older people having a higher likelihood of having never switched. One might expect retirement to increase the probability of having switched due to the greater time available for people to conduct the search and switching process.

Regarding the impact of income, only respondents who did not state their income range had a probability of switching different to those reporting an income of $£ 35,000-49,999^{22}$. Those with higher educational qualifications are less likely to report never switching, but this effect loses its significance when payment method and estimated bill size are controlled for. Beyond being retired, employment status generally has little association with never switching, although the self- employed are more likely to report having switched at some point.

Tenants of a private landlords are more likely to say they had never switched supplier than those who owned their house. Having access to broadband at home ${ }^{23}$ reduced the likelihood of reporting never switching, although, only when payment method and estimated energy expenditure were not included in the regression. It is unsurprising that broadband's significance disappears when payment method is taken into account, since many individuals will have changed payment method when switching supplier. While payment method has the stronger association with having switched, it is likely that broadband and educational attainment increase the probability and ease of searching for cheap energy deals via the Internet which, in turn, increases the probability of both switching and paying by direct debit/standing order. Absence of a gas connection increased the probability of not having switched by over 21 percentage points, even after controlling for other factors.

Paying by any method other than direct debit or standing order was positively correlated with never switching. Interestingly, while prepayment consumers' likelihood of reporting never switching was 13.5-14.7 percentage points higher than for those paying by direct debit/standing order, other more traditional payment methods, such as paying by post, were associated with an even higher probability of reporting never switched. Respondents who reported larger electricity expenditures were more likely to have reported having switched at some point, and this association is non-linear. ${ }^{24}$ One would expect those with larger electricity expenditures (consumption) to be more likely to have switched due to the greater monetary savings available (in absolute terms) providing a greater benefit from investing time in the search and switching process.

\footnotetext{
${ }^{22} £ 35,000-49,999$ is the modal income category if responses of don't know and refused are ignored.

${ }^{23}$ At the time of the survey (2011) about three quarters of households had an internet connection at home (see Flores and Waddams Price, 2018).

${ }^{24}$ In column 3 of Table 1 we report electricity expenditure as a categorical variable to include the large number of respondents who did not know their electricity expenditure in the regressions. This categorical variable also shows a non-linear relationship between estimated electricity expenditure and never switching.
} 
These findings broadly mirror those of other studies which examine who has switched over a shorter period of time, including the CMA (2016b), although this latter source only reported univariate relationships. ${ }^{25}$

\subsubsection{A robustness check using an alternative indicator of inactivity}

As a starting position one might expect consumers who report having never switched to be served by their regional incumbent. For respondents who provided their postcode ${ }^{26}$, we could check whether this was the case. Table 2 shows considerable 'discrepancies' between those who said they had never switched and those who reported a current supplier that matched the identity of their regional incumbent. While 884 respondents (67\% of available observations) gave 'consistent' answers across the two methods, 433 gave apparently inconsistent responses. Around $64 \%$ of those reporting never switching (321 respondents) reported their current supplier was a firm other than their regional incumbent. Additionally, around 14\% (111 respondents) of those reporting that they had switched reported that their supplier was the regional incumbent.

Some of these apparent discrepancies can be explained. First, consumers may have 'inherited' an entrant supplier from an earlier occupant when moving into a house, but have never switched themselves. Second, those consumers reporting having switched but also having the regional incumbent as their current supplier may have switched away from the incumbent and then returned. Nevertheless, that a third of respondents provide 'inconsistent' responses seems notable, and raises some questions about the reliability of the replies in the survey. That nearly two thirds of those who said they had never switched reported that their current supplier was a company other than the incumbent raises particular questions about respondent recall. Were they correctly remembering that they had never switched over this twelve-year period and in error in citing their current supplier? Or had they forgotten about switching and remembered accurately who was presently supplying their electricity? On balance, one might expect greater recall issues with the Never Switched variable as it requires accurate recall over a 12 year period rather than simply recalling a current fact. In either case the recall of individuals, particularly over an extended period, may be a poor guide to which consumers have been persistently inactive.

\begin{tabular}{|l|c|c|c|}
\hline & Not with Incumbent & With Incumbent & Total \\
\hline Have Switched & 700 & 111 & 811 \\
\hline Never Switched & 321 & 184 & 505 \\
\hline Total & 1021 & 295 & 1316 \\
\hline
\end{tabular}

Table 2: Comparing respondents' responses for whether they had never switched and whether they were supplied by the regional electricity incumbent

The survey data available for this research was potentially unusual in that it offered two alternative ways to assess persistent inactivity, in practice only one type of data (i.e. Never Switched or With Incumbent) may be available to researchers and policymakers. In Table A5.2.1 in Appendix 5.2 we report regression results indicating the choice of Never Switched or With Incumbent as the dependent

\footnotetext{
${ }^{25}$ Specifically Figures 2, 3 and 8 of CMA (2016b).

${ }^{26}$ Postcode information was only available for respondents who wished to be informed of the survey results; this subgroup may be unrepresentative of the survey sample as a whole. For some households just knowing their government office region was sufficient to know that their stated current energy supplier was not one of the regional incumbents covering their location.
} 
variable in regressions has a material impact on the types of households identified as persistent nonswitchers. In particular, when 'With Incumbent' is the dependent variable age, renting from a private landlord, being retired and estimated electricity expenditure all lose their statistical significance, compared to when Never Switched is the dependent variable. Also, while households in the West Midlands and Yorkshire and the Humber were associated with a lower probability of never switching than London, households in the South East were associated with a higher probability of reporting being supplied by the regional incumbent.

\section{Conclusions and Policy Implications}

This paper describes the noticeable variation in SCT prices charged by electricity incumbents across the regions of Britain between 1970 and 2016. This highlights that households who display the same behaviour of being are persistently inactive in the energy market, i.e. who remain with their regional incumbent, pay noticeably different prices according to their geographic location. Yet, prior to this work, there has been comparatively little policy concern about, or analysis of, these regional differences, despite the growing focus on the difference between the prices paid by active and inactive consumers. While all regions follow a broadly similar overall time pattern, reflecting the oil crises of the 1970s and broadly falling wholesale energy costs until the mid-2000s, there is a sizeable range in bills across regions, generally around $15-25 \%$ of the national average bill. Averaged across the period studied, consumers who have stayed with the incumbents in South Wales and the South West have faced the highest bills, while those in the north of Scotland have had the lowest bills. However, these regional differences have, if anything, fallen since market liberalisation.

In terms of identifying the types of households that experienced these regional price differences, i.e. the households paying the regional incumbent's SCT, those who reported that they had never switched had characteristics that are largely consistent with earlier research into switching behaviour After controlling for a comprehensive range of factors, older respondents, those renting from a private landlord, those paying by a method other than direct debit/standing order and those not having a gas connection are all associated with an increased probability of reporting never switching. Being retired, living in the West Midlands and reporting higher electricity expenditures are associated with a lower probability of never switching. One exception to the general consistency of the present results with earlier research concerns the impact of age. The present research finds the middle aged are the least likely to report never switching, but earlier research finds this broad age group are also less likely to report switching in the immediate past.

However, caution is needed regarding our ability to conclusively identify the households who are persistently inactive in the energy market from survey data. Our consistency check for identifying those persistently inactive in the energy market: comparing those reporting never switching and those reporting a current supplier that is the regional incumbent showed a substantial discrepancy. Nearly two-thirds of respondents who said they had never switched named a company other than their regional incumbent as their current supplier. Definitively identifying the persistently inactive likely requires access to historic data from suppliers' internal databases. However, the ability of third parties, particularly academics, to analyse such data is reliant on receiving access to this commercially sensitive data from suppliers. This issue is also relevant for the ability of outside parties to verify the findings of Ofgem and the CMA who can use their legal powers to access this type of data.

The results of our consistency check therefore highlight important challenges to the easy identification of those who potentially suffer harm from not engaging with the market over prolonged periods of time. However, our analysis suggests that survey questions to identify persistent non-switching can be improved to address some of reasons why the Never Switched and With Incumbent variables may 
have been inconsistent. First, questions should include a specific time period, perhaps 5 years, over which to assess non-switching. Second, respondents need to be asked whether they were responsible for energy bills throughout the period being assessed. Third, questions are needed to understand the possible impact of house moves in determining a household's energy supplier.

Subject to these caveats our findings provide important information for policymakers about regional inequalities in electricity prices, as well as suggesting the characteristics of those who are least likely to have switched, and so who may be susceptible to paying relatively high electricity prices. However, we only seek to describe these regional differences, rather than to claim that they should necessarily be addressed. Identifying the characteristics of persistently inactive consumers, and the apparent limitations of survey methods in obtaining this knowledge, is important for the accurate impact assessment of policies, such as the price cap recently introduced in the UK retail energy market. While the debate leading up to the price cap focussed on the difference between outcomes for active and inactive consumers, policymakers also need to be aware that there are notable geographic variations in the prices paid by otherwise similar inactive consumers.

\section{References}

Competition and Markets Authority, 2016a. Energy Market Investigation - Final Report, available at: https://assets.publishing.service.gov.uk/media/5773de34e5274a0da3000113/final-reportenergy-market-investigation.pdf (accessed 16 January 2019)

Competition and Markets Authority, 2016b. Energy Market Investigation - Appendix 9.1: CMA domestic customer survey results, available at: https://assets.publishing.service.gov.uk/media/576bcbbc40f0b652dd0000b0/appendix-9-1cma-domestic-customer-survey-results-fr.pdf (accessed 4 February 2019)

Davies, S., C. Waddams Price and C.M.Wilson, 2014. Nonlinear Pricing and Tariff Differentiation: Evidence from the British Electricity Market, The Energy Journal, 35(1), pp. 57-77

Davies, S. and C. Waddams Price, 2007. Does Ownership Unbundling Matter? Evidence from UK Energy Markets, Intereconomics, 42(6), pp. 297-301

Deller, D. and C. Waddams Price, 2018. Energy Affordability in the UK: Corrected Energy Expenditure Shares 1992-2014, CCP Working Paper 18-8, Centre for Competition Policy, University of East Anglia, available at: http://competitionpolicy.ac.uk/documents/8158338/24898393/CCP+WP+18-

8+complete.pdf/4960a073-a343-53c8-9aa2-d5017f78651e (accessed 16 January 2019)

Deller, D., M. Giulietti, G. Loomes, C. Waddams Price, A. Moniche and J.Y. Jeon, 2017. Switching Energy Suppliers: It's Not All About the Money, CCP working paper 17-05, Centre for Competition Policy, University of East Anglia, available at: http://competitionpolicy.ac.uk/documents/8158338/17199160/CCP+WP+175+complete.pdf/fdaaed88-56e5-44f9-98db-6cf161bfb0d4 (accessed 16 January 2019)

Department for Business, Energy and Industrial Strategy, 2017. Statistical dataset - Annual domestic energy bills, available at: https://www.gov.uk/government/statistical-data-sets/annualdomestic-energy-price-statistics (accessed 16 January 2019)

Flores, M and C. Waddams Price, 2018. The Role of Attitudes and Marketing in Consumer Behaviours in the British Retail Electricity Market, The Energy Journal, 39(4), pp. 153-179 
Fouquet, R., 2011. Divergences in Long-Run Trends in the Prices of Energy and Energy Services, Review of Environmental Economics and Policy, 5(2), pp. 196-218

Giulietti, M., C. Waddams Price and M. Waterson, 2005. Consumer Choice and Industrial Policy: a study of UK Energy Markets, The Economic Journal, 115(506), pp. 949-968

Hviid, M. and C. Waddams Price, 2012. Non-discrimination clauses in the retail energy, The Economic Journal, 122, pp. F236-252

Littlechild, S.C., 2012. Ofgem's anticompetitive practice, A response to Ofgem's consultation on the Undue Discrimination Prohibition standard licence condition, available at: https://www.ofgem.gov.uk/ofgem-publications/39598/slc25astephenlittlechild.pdf (accessed 16 January 2019)

Monopolies and Mergers Commission, 1993. Gas and British Gas plc, volume 2 of reports under the Gas and Fair Trading Acts, Cm.2316, HMSO.

Offer, 1998. Reviews of Public Electricity Suppliers 1998 to 2000. Prices and Competition Consultation Paper

Ofgem, 2008. Energy Supply Probe - Initial Findings Reports, Consultation document, available at: https://www.ofgem.gov.uk/ofgem-publications/38437/energy-supply-probe-initial-findingsreport.pdf (accessed 16 January 2019)

Ofgem, 2015. Regional differences in network charges, available at: https://www.ofgem.gov.uk/sites/default/files/docs/2015/10/reg_charges_final_master_versio n_23_october_2015.pdf (accessed 16 January 2019)

Ofgem, 2018. State of the energy market 2018 report, available at: https://www.ofgem.gov.uk/system/files/docs/2018/10/state_of_the_energy_market_report_2 018.pdf (accessed 16 January 2019)

Otero, J. and C. Waddams Price, 2001. Incumbent and entrant response to regulated competition: signalling with accounting costs and market prices, Journal of Economics and Business, Elsevier, vol. 53(2-3), pp. 209-223

Waddams Price, C. and M. Zhu, 2016. Non-discrimination clauses: their effect on GB Retail Energy Prices 2005-2013, The Energy Journal, 37(2), pp. 111-132 


\section{Appendix 1: Incumbent bill size - supplementary information}

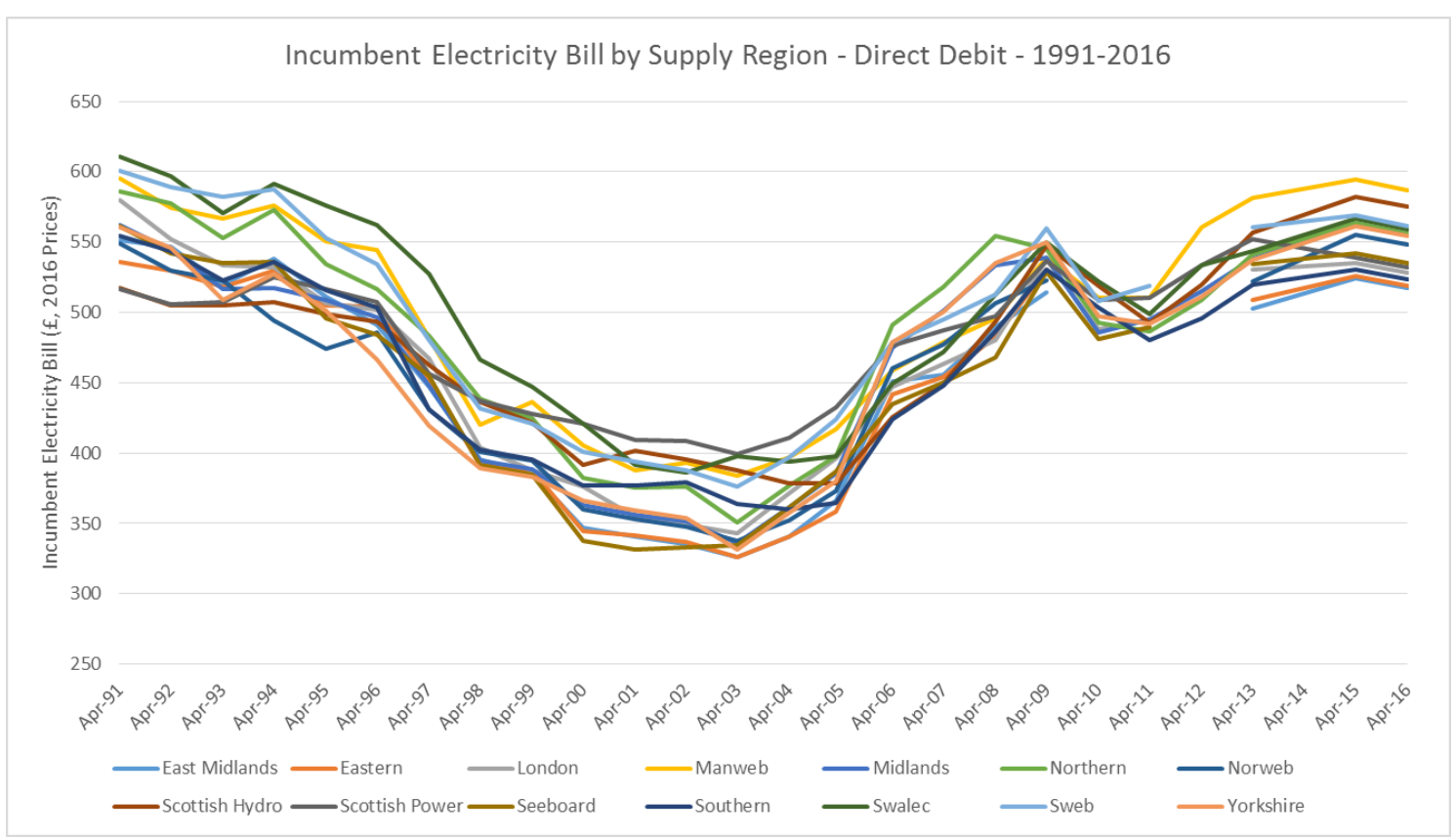

Figure A1: Incumbent bill size by electricity supply region for the direct debit tariff, 3300kWh per year, 1991-2016

Initially direct debit bills were only modestly cheaper than SCT bills, with the saving averaging less than $f 5$ for 1991-1993 and averaging below $f 20$ until 2006. The direct debit saving averaged across regions peaked in 2010 at just over $£ 46$, with the highest saving being just over $£ 85$ for Manweb in 2009. The increase in savings over time probably reflects the allocation of late payment and bad debt costs to SCT customers, costs which had traditionally been recovered from pre-payment meter users (see Otero and Waddams Price, 2001).



Figure A2: Incumbent bill size by electricity supply region for the standard credit tariff, 3300kWh per year, converted to $\mathbf{2 0 1 6}$ prices using the Consumer Price Index 


\section{Appendix 2: Contextualising regional price differentials}

In this appendix we provide context to the regional price differences reported in section 4 rather than attempting to formally demonstrate causation. The evidence presented relates to three factors that could influence incumbent pricing in each region: (i) regional variations in costs, (ii) the pricing behaviour of firms other than the incumbent, and (iii) the proportion of consumers that have switched away from the incumbent.

\section{A2.1 Costs}

One factor behind the lower absolute and relative price differences in more recent years is likely to be the higher proportion of costs which are common across regions, such as tax, government obligations and generation, but there have also been changes in regional distribution and transmission charges ${ }^{27}$. The costs of both transmission (high voltage long distance transport) and distribution (medium and low voltage delivery within area) vary between regions according to the distance from generation sources and local conditions. Ofgem $(2015)^{28}$ concluded that average geographic differences in retail prices were primarily driven by differences in network (transmission and distribution) charges. Figure A3 shows a general positive correlation between network costs and incumbent electricity bills in both 1999 and 2015 which seems to confirm this relationship, although, the relationship appears weaker in 2015.



Figure A3: Energy Bills against Network Costs in 1999 and 2015 29

\footnotetext{
${ }^{27}$ It is difficult to compare the component parts which make up the retail price of electricity across all the years we consider because of accounting changes. For example, before privatisation, transmission was included in the Central Electricity Generating Board's charge for wholesale energy, while recent disaggregation (for example in Ofgem, 2017) combines transmission and distribution into 'network charges'. There were also substantive reallocations of costs between the distribution and retail sectors at the time of market opening.

28 See p. 24

${ }^{29}$ Sources: Offer, 1998 and Ofgem, 2015.
} 


\section{A2.2: Comparing standard credit tariffs between incumbents and entrants}

For the period after markets opened in 1999 we calculated the difference between SCT bills charged by the incumbent and those levied by the cheapest alternative supplier which we could identify in each region. Until 2013 the set of alternative suppliers were the large suppliers included in the Consumer Focus price sheets that provided our source data. While our data covered most suppliers present in the market until 2011, there may have been cheaper offers from smaller suppliers, missed by the price sheets, for 2012 and 2013. For 2015 and 2016 a much broader dataset was available, including the SCTs charged by the many smaller companies who had entered the market by this point. As we are comparing SCTs the differences reported in Figure A6 are likely to be lower than the potential savings available to customers from switching. When switching suppliers, consumers also usually switch tariff type from SCTs to lower priced fixed-term 'teaser' rates.

When the electricity market opened, entrants offered new tariffs in each region, initially in the form of SCTs, which were generally cheaper than the incumbent to attract consumers. Initially, there were many entrants in each region, including the national gas incumbent, British (Scottish) Gas, and the incumbents from other electricity regions. By 2003 exit and consolidation had led to the emergence of the 'Big- 6 ', and for almost a decade the competitors to each regional incumbent were the other four consolidated electricity companies (each the defacto incumbent in one or two other regions), and British Gas. From 2010 entry increased considerably, with over 70 suppliers in the domestic electricity market by June 2018 (Ofgem, 2018).

When non-discrimination clauses were imposed in 2009, the exceptions for introductory offers allowed by the regulator resulted in an enormous increase in fixed-term 'teaser' rates (Littlechild, 2012). As fixed-term tariffs have become more pervasive, the SCTs which we describe have become default charges for consumers who do not switch once the cheaper (introductory) offer expires. Since electricity tariffs are 'two-part tariffs' consisting of a fixed charge per day and a separate unit charge per kWh, the competitiveness of different firms may vary by consumption level. For consistency, we continue to compare bills for an annual consumption of $3,300 \mathrm{kWh}^{30}$.

\footnotetext{
${ }^{30}$ Tariffs can be adjusted to attract high (low) energy users by increasing (reducing) the fixed charge relative to the unit charge, even when the bill for the average consumer remains constant. The Big- 6 seemed to divide the market in this way in the mid-2000s (see Davies et al., 2014).
} 


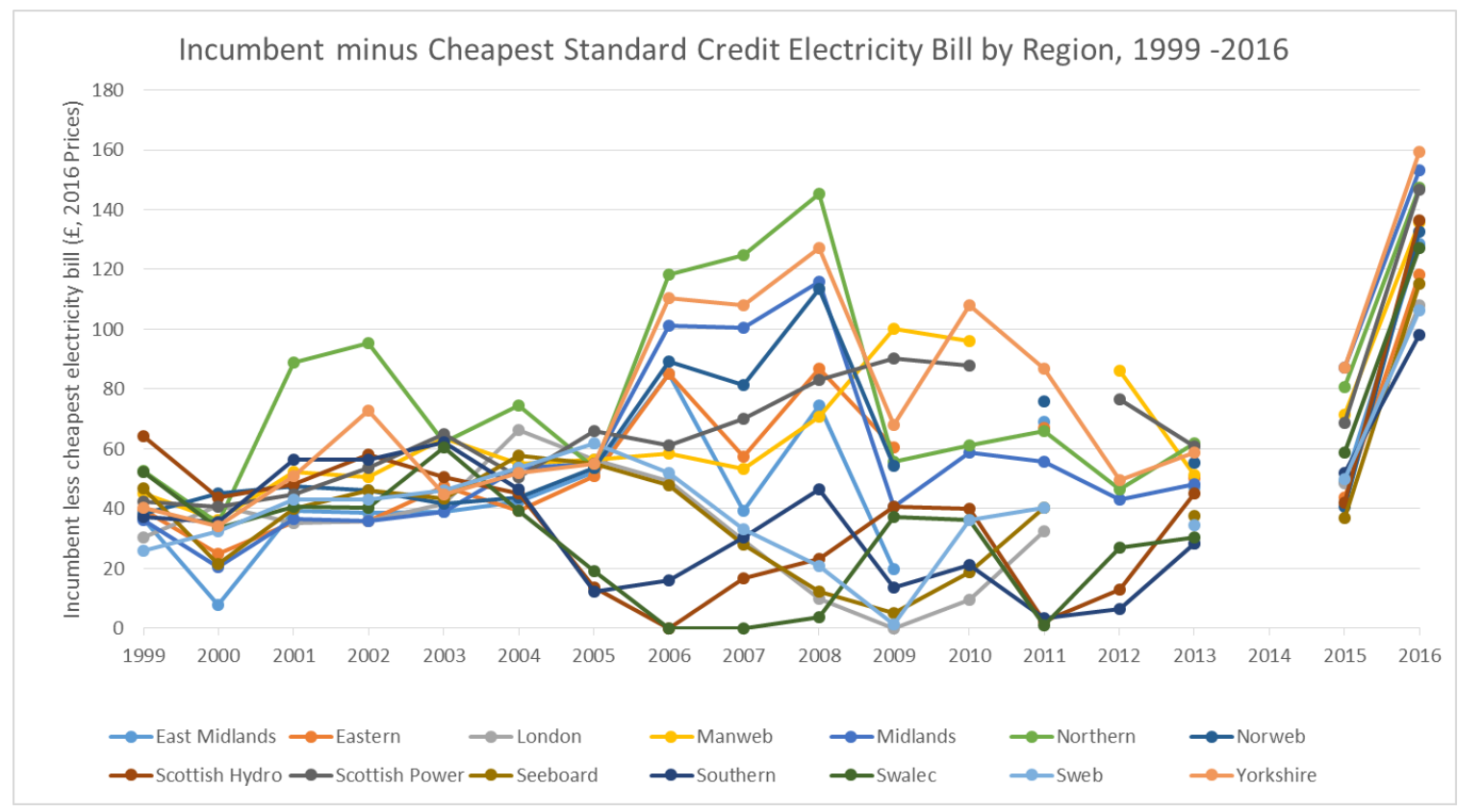

Figure A4: Difference between the cheapest SCT and the incumbent's SCT bill in each region

Figure A4 shows considerable variation both across regions and over time in the difference between the incumbent's SCT and the cheapest entrant's SCT in each region. Between 2005 and 2008, there is a substantial increase in the regional variation observed. For example, in 2006 and 2007 the incumbent in the Swalec region offered the cheapest SCT in its region, while in 2008 the incumbent in the Northern region had an SCT $£ 145$ more expensive than that of the cheapest entrant.

The introduction of non-discrimination clauses in 2009, which limited the variation in the prices charged by the five consolidated electricity companies in different regions, generated a convergence between entrants' and incumbents' prices across regions (Hviid and Waddams Price, 2012; Waddams Price and Zhu, 2016). This convergence is visible in the reduction in the difference between incumbent and entrant SCTs in the majority (but not all) of the regions in Figure A4. It is also noticeable that the gap between the cheapest entrants' and incumbents' SCTs increases markedly in all regions between 2015 and 2016, possibly reflecting the increasing number of entrants.

Figure A5 averages the difference between the incumbent SCT and that of the cheapest entrant in each region across the period 1999 to 2016. Unsurprisingly, given Figure A4, the largest average gap occurs in the Northern region at just over $f 80$ per annum, while the average gap is just under $£ 36$ in the Swalec region. These average gaps respectively represent $16 \%$ and $8 \%$ of the cheapest SCT in each region.

Overall, the regional variation in these SCT differences is substantial, and we note that consumers in South Wales (Swalec) faced both the highest incumbent charges between 1994 and 2003, and the smallest difference between the SCTs offered by the incumbent and the entrants. While the incumbent's high bill is explained at least partly by higher network costs, the small gap relative to entrants is likely influenced by a range of other factors, including demand side features. 




Figure A5: Difference in SCT bills between the incumbent and the cheapest entrant averaged across 1999 to 2016 by region

\section{A2.3: The proportion of consumers remaining with the regional incumbent}

Figure A6 shows the proportion of consumers who stayed with the incumbent in each region and, thus, paid the prices discussed in the main text. Again we find considerable differences across regions. The regional incumbent's market share declines over time in each region as one would expect, but at different rates in each region. As early as 2000 , there was a 20 percentage point difference in incumbent market shares across the regions, with Scottish Hydro retaining the highest market share and Manweb the lowest. By 2016 this difference across regions had approximately doubled to 40 percentage points, with Scottish Hydro again having the highest incumbent market share $(72 \%)$ and Midlands the lowest (32\%). The high market share of Scottish Hydro is likely to be partly explained by the much lower penetration of the gas network in this region. Lower gas penetration means fewer customers had a relationship with the gas incumbent, who attracted many switching consumers in other regions. ${ }^{31}$

\footnotetext{
${ }^{31}$ Higher incumbent market shares also seemed associated with the incumbent retailer and regional distribution company being owned by a common entity (Davies and Waddams Price, 2007), although, formal causality was not demonstrated. There are strict rules on the separation of retail and distribution businesses and to ensure non-discrimination between different users of the network.
} 




Figure A6: Incumbent market share for standard credit tariffs by region, 2000-2016 ${ }^{32}$

An interesting feature of Figure A6 is that the three regions where Scottish and Southern owns the incumbent (Scottish Hydro, Swalec and Southern), are the three regions (after 2005) where the incumbent retained the highest market share.

The regional pattern is similar for direct debit consumers (see Figure A7), with the range in incumbent market shares across regions being similar to that for SCTs. However, the general level of incumbent market shares for direct debit tariffs is around 10 percentage points lower than for SCTs. The lower market shares for direct debit tariffs is to be expected as direct debit is the most common payment method for switchers.

\footnotetext{
32 Source: Percentage of domestic electricity customers by region by supplier type (QEP 2.4.1), Statistical dataset- Quarterly domestic energy customer numbers, Department of Business, Energy and Industrial Strategy, available at: https://www.gov.uk/government/statistical-data-sets/quarterly-domestic-energy-pricestastics
} 




Figure A7 Incumbent market share for direct debit tariffs by region, 2000-2016

${ }^{33}$ Source: see previous footnote. 


\section{Appendix 3: Supplementary regression results}

\section{A3.1 Univariate regression results}

Regression 1 Regression 2 Regression 3

\begin{tabular}{l|ccc}
\hline Age & $0.002^{* * *}$ & \\
\hline Age & \multicolumn{3}{|c}{$-0.021^{* * *}$} \\
Age squared & \multicolumn{3}{c}{$0.000^{* * *}$} \\
\hline Age combined effect (quadratic) & & & 0.001 \\
\hline $\mathrm{N}$ & 1766 & 1766 & 1766 \\
Log likelihood & -1194.13 & -1185.34 & -1185.34 \\
P-value, LR test joint significance & 0.003 & 0.000 & 0.000 \\
\hline
\end{tabular}

Notes: $*$ indicates statistical significance at the $10 \%$ level, $* *$ indicates significance at the $5 \%$ level, and $* * *$ indicates signifcance at the $1 \%$ level. The table reports the average marginal effects associated with the probability of reporting having never switched electricity supplier.

Table A3.1.1 - Average marginal effect of age on the probability of reporting Never Switched

\begin{tabular}{|c|c|}
\hline Income: below f6,499 & $0.187^{* * *}$ \\
\hline Income: $€ 6,500-7,499$ & $0.245^{* * *}$ \\
\hline Income: $£ 7,500-9,499$ & $0.167^{* *}$ \\
\hline Income: $£ 9,500-11,499$ & $0.196 * * *$ \\
\hline Income: $£ 11,500-13,499$ & -0.003 \\
\hline Income: $£ 13,500-15,499$ & 0.029 \\
\hline Income: $£ 15,500-17,499$ & 0.093 \\
\hline Income: f17,500-19,999 & $0.119 *$ \\
\hline Income: £20,000-24,999 & 0.074 \\
\hline Income: $£ 25,000-34,999$ & $0.138^{* *}$ \\
\hline Income: $£ 35,000-49,999$ & - \\
\hline Income: f50,000-74,999 & 0.046 \\
\hline Income: f75,000-99,999 & 0.027 \\
\hline Income $£ 100,000+$ & 0.024 \\
\hline Income: Don't know & $0.206^{* * *}$ \\
\hline Income: Refused & $0.196 * * *$ \\
\hline $\bar{N}$ & 1766 \\
\hline Log likelihood & -1175.57 \\
\hline P-value, LR test joint significance & 0.000 \\
\hline \multicolumn{2}{|c|}{$\begin{array}{l}\text { Notes: }{ }^{*} \text { indicates statistical significance at the } 10 \% \\
\text { level, }{ }^{* *} \text { indicates significance at the } 5 \% \text { level, and } \\
* * * \text { indicates signifcance at the } 1 \% \text { level. The table } \\
\text { reports the average marginal effects associated with } \\
\text { the probability of reporting having never switched } \\
\text { electricity supplier. Bold indicates the base category. }\end{array}$} \\
\hline
\end{tabular}

Table A3.1.2 - Average marginal effect of income on the probability of reporting Never Switched 


\begin{tabular}{l|c}
\hline No Qualifications & - \\
$\begin{array}{l}\text { O-Level, A-Level, HNC, GNVQ, } \\
\text { NVQ/SVQ Level 1-3, GCSE, CSE, }\end{array}$ & $-0.121^{* * *}$ \\
$\begin{array}{l}\text { City \& Guilds } \\
\text { Degree, Postgraduate, NVQ/SVQ } \\
\text { Level 4, HND, HNVQ }\end{array}$ & $-0.157^{* * *}$ \\
Refused & -0.014 \\
\hline $\mathrm{N}$ & 1766 \\
$\begin{array}{l}\text { Log likelihood } \\
\text { P-value, LR test joint significance }\end{array}$ & -1184.88 \\
\hline $\begin{array}{l}\text { Notes: }{ }^{*} \text { indicates statistical significance at the } 10 \% \\
\text { level, } * * \text { indicates significance at the } 5 \% \text { level, and } * * *\end{array}$ \\
$\begin{array}{l}\text { indicates signifcance at the } 1 \% \text { level. The table reports } \\
\text { the average marginal effects associated with the } \\
\text { probability of reporting having never switched } \\
\text { electricity supplier. Bold indicates the base category. }\end{array}$
\end{tabular}

Table A3.1.3 - Average marginal effect of educational qualifications on the probability of reporting Never Switched

\begin{tabular}{|c|c|}
\hline Being Bought on Mortgage & $-0.083 * * *$ \\
\hline Owned Outright & - \\
\hline Rented from Local & \\
\hline Authority/Housing Association & 0.048 \\
\hline Rented from Private Landlord & $0.180 * * *$ \\
\hline Other & 0.118 \\
\hline $\mathrm{N}$ & 1766 \\
\hline Log likelihood & -1176.88 \\
\hline P-value, LR test joint significance & 0.000 \\
\hline \multicolumn{2}{|c|}{$\begin{array}{l}\text { Notes: }{ }^{*} \text { indicates statistical significance at the } \\
10 \% \text { level, } * * \text { indicates significance at the } 5 \% \\
\text { level, and } * * * \text { indicates signifcance at the } 1 \% \\
\text { level. The table reports the average marginal } \\
\text { effects associated with the probability of } \\
\text { reporting having never switched electricity } \\
\text { supplier. Bold indicates the base category. }\end{array}$} \\
\hline
\end{tabular}

Table A3.1.4 - Average marginal effect of tenure on the probability of reporting Never Switched 


\begin{tabular}{l|c}
\hline Broadband: Yes & - \\
Broadband: No & $0.165^{* * *}$ \\
\hline $\mathrm{N}$ & 1766 \\
Log likelihood & -1180.02 \\
P-value, LR test joint significance & 0.000 \\
\hline Notes: ${ }^{*}$ indicates statistical significance at the \\
$10 \%$ level, ${ }^{* *}$ indicates significance at the 5\% \\
level, and ${ }^{* * *}$ indicates signifcance at the $1 \%$ \\
level. The table reports the average marginal \\
effects associated with the probability of \\
reporting having never switched electricity \\
supplier. Bold indicates the basecategory.
\end{tabular}

Table A3.1.5 - Average marginal effect of broadband in the home on the probability of reporting Never Switched

\begin{tabular}{l|c}
\hline Eastern & $-0.148^{* * *}$ \\
East Midlands & $-0.128^{* *}$ \\
London & - \\
North West & -0.061 \\
North East & $-0.114^{*}$ \\
Scotland & -0.034 \\
South East & -0.068 \\
South West & $-0.096^{*}$ \\
Wales & 0.047 \\
West Midlands & $-0.204^{* * *}$ \\
Yorkshire and the Humber & $-0.117^{* *}$ \\
\hline $\mathrm{N}$ & 1766 \\
Log likelihood & -1183.27 \\
P-value, LR test joint significance & 0.001 \\
\hline Notes: $*$ indicates statistical significance at the \\
$10 \%$ level, ** indicates significance at the $5 \%$ \\
level, and *** indicates signifcance at the $1 \%$ \\
level. The table reports the average marginal \\
effects associated with the probability of \\
reporting having never switched electricity \\
supplier. Bold indicates the base category.
\end{tabular}

Table A3.1.6 - Average marginal effect of government office region on the probability of reporting Never Switched 


\begin{tabular}{l|c}
\hline Detached & - \\
Semi-detached & -0.029 \\
Terraced & 0.001 \\
Flat & $0.137^{* * *}$ \\
Other & -0.056 \\
\hline $\mathrm{N}$ & 1766 \\
Log likelihood & -1190.34 \\
P-value, LR test joint significance & 0.003 \\
\hline
\end{tabular}

Notes: * indicates statistical significance at the $10 \%$ level, ** indicates significance at the $5 \%$ level, and $* * *$ indicates signifcance at the $1 \%$ level. The table reports the average marginal effects associated with the probability of reporting having never switched electricity supplier. Bold indicates the base category.

Table A3.1.7 - Average marginal effect of dwelling type on the probability of reporting Never Switched

\begin{tabular}{l|c}
\hline Metropolitan & - \\
Other 100\% Urban & -0.038 \\
Mixed Urban/Rural & $-0.100 * * *$ \\
Rural & 0.047 \\
\hline $\mathrm{N}$ & 1766 \\
Log likelihood & -1188.67 \\
P-value, LR test joint significance & 0.000 \\
\hline Notes: * indicates statistical significance at the \\
10\% level, ** indicates significance at the $5 \%$ \\
level, and *** indicates signifcance at the $1 \%$ \\
level. The table reports the average marginal \\
effects associated with the probability of \\
reporting having never switched electricity \\
supplier. Bold indicates the base category.
\end{tabular}

Table A3.1.8 - Average marginal effect of area type on the probability of reporting Never Switched 


\begin{tabular}{l|c}
\hline Employed full-time & - \\
Employed part-time & -0.031 \\
Self-employed & -0.073 \\
Retired & 0.012 \\
Not able to work & 0.064 \\
Unemployed & 0.034 \\
Other/Still in education & -0.016 \\
\hline $\mathrm{N}$ & 1766 \\
Log likelihood & -1195.78 \\
P-value, LR test joint significance & 0.490 \\
\hline
\end{tabular}

Notes: * indicates statistical significance at the $10 \%$ level, $* *$ indicates significance at the $5 \%$ level, and $* * *$ indicates signifcance at the $1 \%$ level. The table reports the average marginal effects associated with the probability of reporting having never switched electricity supplier. Bold indicates the base category.

Table A3.1.9 - Average marginal effect of employment status on the probability of reporting Never Switched

\begin{tabular}{l|c}
\hline Gas Connection: No & $0.243^{* * *}$ \\
Gas Connection: Yes & - \\
\hline $\mathrm{N}$ & 1766 \\
Log likelihood & -1179.56 \\
P-value, LR test joint significance & 0.000 \\
\hline
\end{tabular}

Notes: * indicates statistical significance at the $10 \%$ level, $* *$ indicates significance at the $5 \%$ level, and $* * *$ indicates signifcance at the $1 \%$ level. The table reports the average marginal effects associated with the probability of reporting having never switched electricity supplier. Bold indicates the base category.

Table A3.1.10 - Average marginal effect of having a gas connection on the probability of reporting Never Switched 


\begin{tabular}{|c|c|}
\hline Direct Debit /Standing Order & - \\
\hline $\begin{array}{l}\text { Telephone with debit/credit } \\
\text { card }\end{array}$ & 0.076 \\
\hline $\begin{array}{l}\text { In person at post office } \\
\text { /bank/building society }\end{array}$ & $0.253^{* * *}$ \\
\hline $\begin{array}{l}\text { Over the internet with } \\
\text { credit/debit card }\end{array}$ & $0.148^{* *}$ \\
\hline By post & $0.295^{* * *}$ \\
\hline Pre-payment & $0.155^{* * *}$ \\
\hline $\begin{array}{l}\text { Other/ Unclear/DK/Fuel direct } \\
\text { from benefits }\end{array}$ & $0.314^{* *}$ \\
\hline$N$ & 1766 \\
\hline Log likelihood & -1163.52 \\
\hline P-value, LR test joint significance & 0.000 \\
\hline \multicolumn{2}{|c|}{$\begin{array}{l}\text { Notes: * indicates statistical significance at the } \\
10 \% \text { level, } * * \text { indicates significance at the } 5 \% \\
\text { level, and } * * * \text { indicates signifcance at the } 1 \% \\
\text { level. The table reports the average marginal } \\
\text { effects associated with the probability of } \\
\text { reporting having never switched electricity } \\
\text { supplier. Bold indicates the base category. }\end{array}$} \\
\hline
\end{tabular}

Table A3.1.11 - Average marginal effect of payment method on the probability of reporting Never Switched 


\begin{tabular}{|c|c|c|c|c|}
\hline & \multicolumn{4}{|c|}{ Regression 1 Regression 2 Regression 3 Regression 4} \\
\hline Electricity expenditure - linear & 0.000 & & & \\
\hline Electricity expenditure - linear & & $-0.000 * * *$ & & \\
\hline Electricity expenditure - squared & & $0.000 * * *$ & & \\
\hline $\begin{array}{l}\text { Electricity expenditure - (continuous, } \\
\text { quadratic, } £ 100 \text { units) }\end{array}$ & & & $-0.018 * * *$ & \\
\hline Estimated expenditure: Don't Know & & & & 0.072 \\
\hline Up to $£ 200$ & & & & $0.161^{* *}$ \\
\hline f199 to $f 300$ & & & & 0.081 \\
\hline$£ 299$ to $£ 400$ & & & & - \\
\hline$£ 399$ to $£ 500$ & & & & 0.006 \\
\hline$f 499$ to $f 600$ & & & & -0.009 \\
\hline f599 to $£ 700$ & & & & -0.008 \\
\hline$f 699$ to $f 800$ & & & & -0.080 \\
\hline$f 799$ to $f 900$ & & & & -0.086 \\
\hline f899 to $£ 1000$ & & & & -0.099 \\
\hline$£ 999$ to $£ 1200$ & & & & $-0.142 * *$ \\
\hline$£ 1199$ to $f 1400$ & & & & $-0.152^{* * *}$ \\
\hline$£ 1399$ to $£ 2400$ & & & & $-0.151^{* * *}$ \\
\hline f2400 and over & & & & 0.083 \\
\hline $\bar{N}$ & 1435 & 1435 & 1435 & 1766 \\
\hline Log likelihood & -961.488 & -942.430 & -942.430 & -1170.48 \\
\hline P-value, LR test joint significance & 0.683 & 0.000 & 0.000 & 0.000 \\
\hline
\end{tabular}

Notes: ${ }^{*}$ indicates statistical significance at the $10 \%$ level, ${ }^{* *}$ indicates significance at the $5 \%$ level, and *** indicates signifcance at the $1 \%$ level. The table reports the average marginal effects associated with the probability of reporting having never switched electricity supplier. Bold indicates the base category.

Table A3.1.12 - Average marginal effect of electricity expenditure on the probability of reporting Never Switched 
A3.2 Comparing Never Switched and With Incumbent regressions

\begin{tabular}{|c|c|c|c|c|c|c|}
\hline & $\begin{array}{c}\text { Never } \\
\text { Switched } 1 \\
\end{array}$ & $\begin{array}{c}\text { Never } \\
\text { Switched } 2\end{array}$ & $\begin{array}{c}\text { Never } \\
\text { Switched } 3\end{array}$ & \begin{tabular}{|c} 
With \\
Incumbent 1
\end{tabular} & $\begin{array}{c}\text { With } \\
\text { Incumbent } 2\end{array}$ & $\begin{array}{c}\text { With } \\
\text { Incumbent } 3\end{array}$ \\
\hline Age linear & -0.011 & $-0.015^{*}$ & -0.010 & 0.007 & 0.005 & 0.007 \\
\hline Age squared & $0.000 *$ & $0.000 * *$ & $0.000 *$ & -0.000 & -0.000 & -0.000 \\
\hline Income: $f 9,500-11,499$ & 0.068 & 0.003 & 0.037 & 0.092 & $0.162^{* *}$ & 0.084 \\
\hline Income: $£ 11,500-13,499$ & -0.083 & $-0.130 *$ & -0.109 & 0.110 & $0.189^{* *}$ & 0.098 \\
\hline Income: $£ 15,500-17,499$ & 0.006 & 0.055 & -0.003 & 0.083 & $0.144^{*}$ & 0.079 \\
\hline Income: $£ 25,000-34,999$ & $0.118^{* *}$ & 0.095 & $0.104^{*}$ & 0.007 & 0.035 & -0.005 \\
\hline Income: $₫ 35,000-49,999$ & - & - & - & - & - & - \\
\hline Income: Refused & $0.122 * *$ & $0.127^{* *}$ & $0.098^{*}$ & -0.018 & 0.028 & -0.028 \\
\hline No Qualifications & - & - & - & - & - & - \\
\hline $\begin{array}{l}\text { O-Level, A-Level, HNC, GNVQ, } \\
\text { NVQ/SVQ Level 1-3, GCSE, CSE, } \\
\text { City \& Guilds }\end{array}$ & -0.027 & 0.037 & -0.005 & -0.025 & -0.011 & -0.014 \\
\hline $\begin{array}{l}\text { Degree, Postgraduate, NVQ/SVQ } \\
\text { Level } 4, H N D, H N V Q\end{array}$ & -0.043 & 0.011 & -0.022 & -0.032 & -0.007 & -0.020 \\
\hline Refused & - & - & - & - & - & - \\
\hline Owned Outright & - & - & - & - & - & - \\
\hline Rented from Private Landlord & $0.142 * *$ & $0.101^{*}$ & $0.112^{* *}$ & 0.012 & -0.020 & -0.000 \\
\hline East Midlands & 0.007 & -0.008 & 0.024 & 0.107 & $0.177^{* *}$ & 0.104 \\
\hline London & - & - & - & - & - & - \\
\hline Scotland & -0.049 & -0.021 & -0.042 & $0.123 *$ & $0.137^{*}$ & 0.119 \\
\hline South East & 0.076 & 0.029 & 0.072 & $0.152^{* *}$ & $0.156^{* *}$ & $0.144^{* *}$ \\
\hline West Midlands & $-0.157^{* * *}$ & $-0.149 * *$ & $-0.145^{* *}$ & 0.035 & 0.075 & 0.039 \\
\hline Yorkshire and the Humber & $-0.104 *$ & $-0.133^{* *}$ & $-0.104 *$ & 0.024 & 0.036 & 0.017 \\
\hline Broadband: Yes & - & - & - & - & - & - \\
\hline Broadband: No & $0.070^{*}$ & 0.048 & 0.040 & 0.038 & 0.055 & 0.031 \\
\hline Detached & - & - & - & - & - & - \\
\hline Terraced & -0.042 & -0.043 & -0.058 & $-0.086 * *$ & -0.066 & $-0.091 * *$ \\
\hline Other & $-0.183^{*}$ & $-0.198 * *$ & $-0.220 * *$ & -0.111 & $-0.130 *$ & -0.118 \\
\hline Metropolitan & - & - & - & - & - & - \\
\hline Other $100 \%$ Urban & $-0.138 * * *$ & $-0.109 * *$ & $-0.140 * * *$ & 0.007 & 0.003 & 0.013 \\
\hline Mixed Urban/Rural & $-0.157^{* * *}$ & $-0.163^{* * *}$ & $-0.172 * * *$ & -0.015 & -0.033 & -0.015 \\
\hline Rural & -0.036 & -0.043 & -0.047 & 0.028 & 0.022 & 0.035 \\
\hline Married & - & - & - & - & - & - \\
\hline Living with Partner & 0.072 & 0.045 & $0.082^{*}$ & 0.076 & $0.098^{*}$ & $0.080^{*}$ \\
\hline Singled & 0.049 & 0.050 & 0.037 & 0.020 & 0.025 & 0.029 \\
\hline Widowed & $0.110^{* *}$ & $0.135^{* *}$ & $0.094 *$ & -0.043 & -0.036 & -0.043 \\
\hline Separated & 0.087 & 0.044 & 0.050 & -0.043 & -0.017 & -0.052 \\
\hline Divorced & -0.021 & -0.030 & -0.013 & -0.048 & -0.037 & -0.034 \\
\hline Employed full-time & - & - & - & - & - & - \\
\hline Self-employed & $-0.107^{* *}$ & -0.090 & $-0.100 *$ & 0.037 & 0.023 & 0.028 \\
\hline Retired & $-0.177^{* * *}$ & $-0.169 * * *$ & $-0.175^{* * *}$ & -0.031 & -0.041 & -0.035 \\
\hline Gas Connection: No & $0.242^{* * *}$ & $0.266 * * *$ & $0.257^{* * *}$ & $0.172^{* * *}$ & $0.150 * * *$ & $0.154^{* * *}$ \\
\hline Gas Connection: Yes & - & - & - & - & - & - \\
\hline Direct Debit /Standing Order & & - & - & & - & - \\
\hline $\begin{array}{l}\text { In person at post office } \\
\text { /bank/building society }\end{array}$ & & $0.175^{* * *}$ & $0.176^{* * *}$ & & $0.103^{* *}$ & $0.123 * * *$ \\
\hline $\begin{array}{l}\text { Over the internet with } \\
\text { credit/debit card }\end{array}$ & & $0.145^{*}$ & $0.150 * *$ & & $0.206^{* *}$ & $0.174^{* *}$ \\
\hline By post & & $0.190^{*}$ & $0.179 * *$ & & 0.110 & 0.087 \\
\hline Pre-payment & & $0.105^{* *}$ & $0.124^{* *}$ & & 0.072 & $0.089 *$ \\
\hline
\end{tabular}

(continued on next page) 


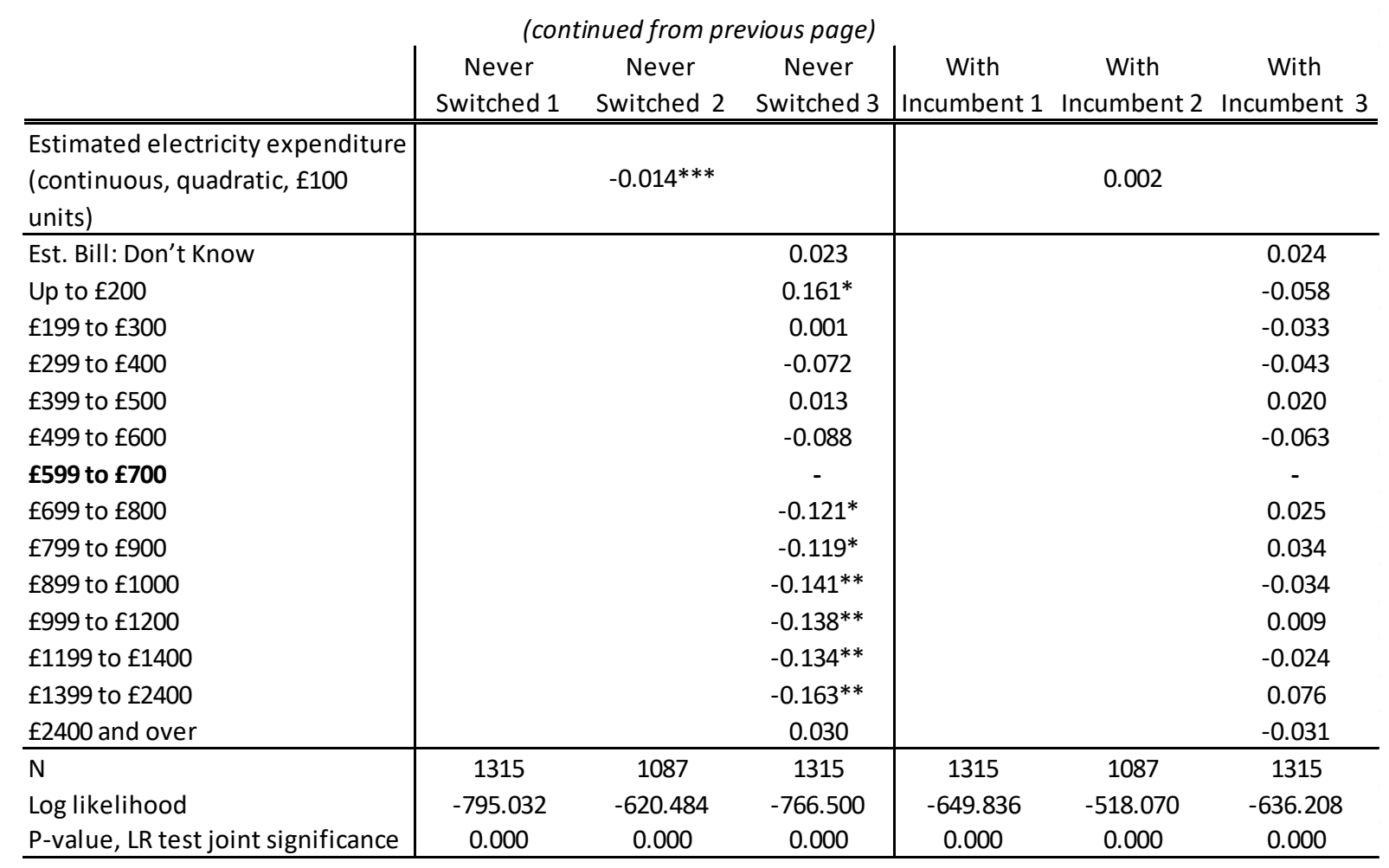

Notes: ${ }^{*}$ indicates statistical significance at the $10 \%$ level, ${ }^{* *}$ indicates significance at the $5 \%$ level, and ${ }^{* * *}$ indicates signifcance at the $1 \%$ level. Bold indicates the base category for categorical variables. The first three columns report the average marginal effects associated with the probability of reporting having never switched electricity supplier. The second set of three columns report the average marginal effects of a respondent's stated current electricity supplier being the regional incumbent. We focus on reporting the categories of variables that showed significance at the $5 \%$ level in at least some of the multivariate regressions. Where the table includes a blank space the specified variable was not included in the specified regression. Additional variables included in the regressions, but where none of the categories were significant at the $5 \%$ level are: respondent gender and whether has children. The number of observations drops in the second and fifth columns because using the continuous electricity expenditure variable involves dropping responses of 'don't know' regarding electricity expenditure. The regressions are based on the subset of survey respondents for whom their electricity supply region could be identified, generally this was where a respondent was willing to provide their postcode when answering the survey.

Table A3.2.1 - Average marginal effects on the probability of reporting: (i) Never Switched and (ii) With Incumbent 